\title{
Effect of $\pi$-System Extension on the Ionization Energy of the Planar Blatter Radical: Experimental and Theoretical Studies
}

\author{
Published as part of The Journal of Physical Chemistry virtual special issue "Josef Michl Festschrift". \\ Aniket A. Hande, Patrick Baylère, Piotr Kaszyński,* and Anna Chrostowska*
}

ACCESS I

Wl Metrics \& More

| 回 Article Recommendations

Supporting Information

ABSTRACT: Fusion of benzene, naphthalene, and phenalene rings with the $\mathrm{D}$ ring of the planar Blatter radical leads to extension of the $\pi$-system and increased spin delocalization. The effect of this $\pi$-extension and the position of the ring fusion on the electronic structure of the radicals was investigated by UV-photoelectron spectroscopy and DFT CAM-B3LYP/6-311G(d,p) method. The experimental data obtained for 3 out of 8 derivatives were correlated with DFT-derived ionization energies.
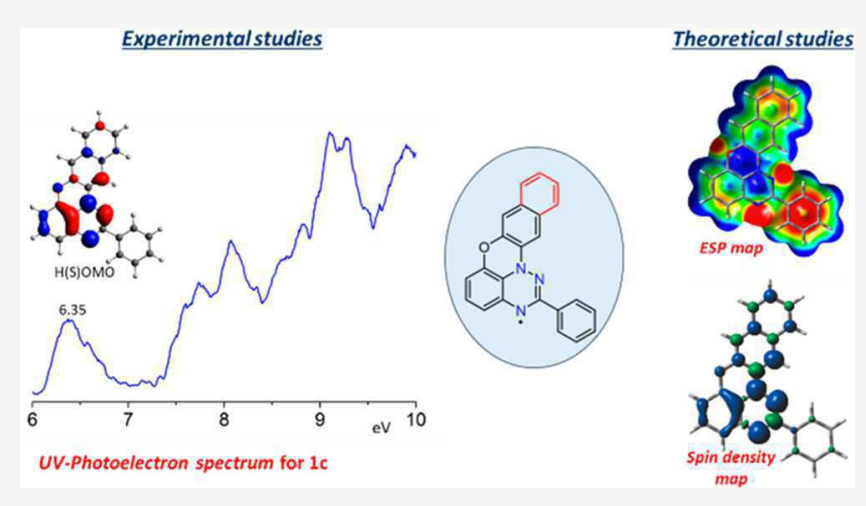

\section{INTRODUCTION}

Advances in chemistry of 1,4-dihydrobenzo[e][1,2,4]triazin-4$\mathrm{yl}$ radicals, ${ }^{1}$ derivatives of the prototypical Blatter radical ${ }^{2}$ (A, Figure 1), have opened up access to functional paramagnetic materials and enabled their investigation in such fields as spintronics, ${ }^{3,4}$ near-IR sensing, ${ }^{5}$ and organic electronics. ${ }^{6}$ The newest developments are in the area of the planar Blatter radical $^{7}$ 1a (Figure 1) and its derivatives, ${ }^{8,9}$ which offer not only planarity and greater spin delocalization but also tunability of properties by judicious choice of substituents and $\pi$-system extension. Radical 1a can also be considered as the central structural element of a class of paramagnetic subnanographenes, formally obtained by fusing its B and D rings with (het)aromatic systems.

Planar radical $\mathbf{1 a}$ is an attractive new platform for preparation of functional materials. For instance, appropriately functionalized derivatives of 1a have been shown to form paramagnetic and switchable antiferroelectric liquid crystalline phases. $^{10}$ Further applications of $1 \mathbf{a}$ and its derivatives, especially in surface science, require the knowledge of their electronic structures and ionization energies in particular, and also the extent of tunability of their molecular properties. In this context we have recently obtained gas phase vertical ionization energies for a series of $\mathrm{C}(10)$-substitited derivatives of $1 \mathrm{a}$ and correlated them with solution electrochemical potentials and optical band gap energies. ${ }^{11}$ On the other hand, the effect of expansion of the $\pi$-system in 1a on these properties is still uncharted. To fill in this gap we focused on three recently available ${ }^{9}$ benzene-fused derivatives $\mathbf{1 b}-\mathbf{1 d}$ and their naphthalene and phenalene analogues $(\mathbf{1} \mathbf{e}-\mathbf{1 h}$, Figure 1$)$ to asses impacts of the $\pi$-extension in the "upper" part ( $\operatorname{ring} \mathrm{D}$ ) of the planar radical 1a on properties, and set out to develop tools for predicting such properties for even larger paramagnetic $\pi$ systems.

Herein we report experimental $(\mathbf{1} \mathbf{a}-\mathbf{1 d})$ and DFT $(\mathbf{1} \mathbf{a}-\mathbf{1 h})$ investigation of a series of derivatives of the parent planar Blatter radical 1a with $\pi$-extension in the $\mathrm{D}$ ring. The $\pi$ extension is obtained by fusing benzene $(\mathbf{1 b}-\mathbf{1 d})$ and naphthalene rings $(\mathbf{1 e - 1 g})$ at the $k, l$, or $m$ edges or by periannulation of phenalene at the $k$ and $l$ edges $(\mathbf{l h})$ of the parent 1a (Figure 1). For two of the three known derivatives, 1c and 1d, vertical ionization energies were measured using UV-photoelectron spectroscopy. The entire series was investigated using density functional theory (DFT), theoretical $\mathrm{IE}_{n}$ were compared to the experimental data for A, 1a, 1c, and 1d, and the correlation was used to predict first ionization energies for other members of the series. Spin delocalization and $\mathrm{IE}_{1}$ were analyzed in the context of the ring size and position of its fusion. 


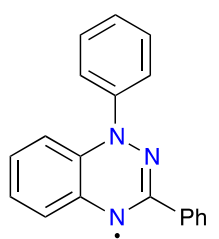

A

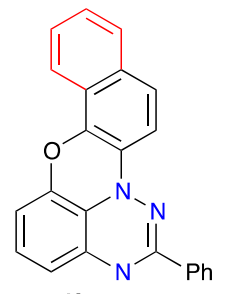

$1 b$

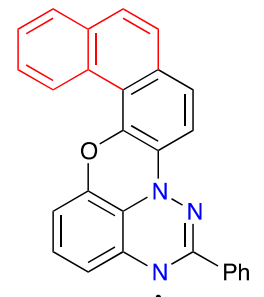

$1 \mathrm{e}$

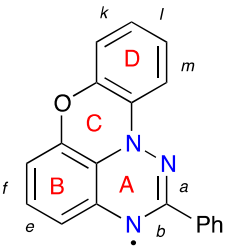

$1 \mathbf{a}$

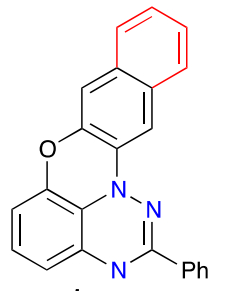

1c $\cdot$

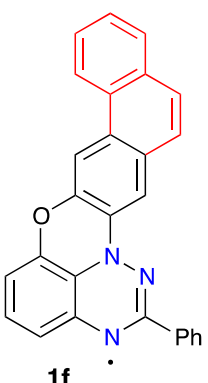

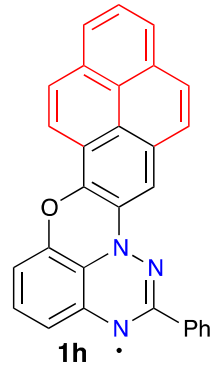

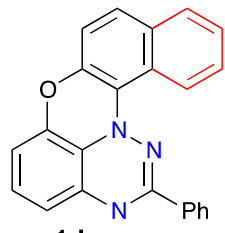

1d.

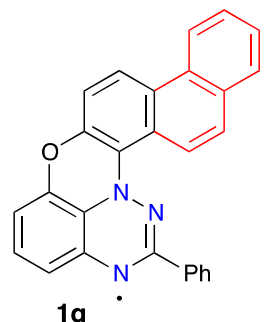

$1 \mathrm{~g}$
Figure 1. Structures of Blatter radical A and planar Blatter radical derivatives $\mathbf{1}$. Rings and edges are labeled in $\mathbf{1}$ a and rings fused to the parent $1 \mathrm{a}$ are shown in red.

\section{EXPERIMENTAL AND COMPUTATIONAL} METHODS

Materials. Radicals $\mathbf{1 b} \mathbf{- 1} \mathbf{d}$ were obtained from appropriate precursors $\mathbf{2}$ as shown in Scheme 1 and described elsewhere.

Scheme 1. Synthesis of Radicals $1 b-1 d$ According to Ref 9

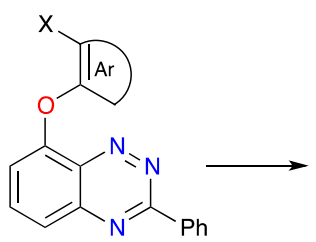

conditions: $\mathrm{X}=\mathrm{H}$ $\mathrm{CH}_{2} \mathrm{Cl}_{2}$, halogen lamp (300 W)

$\operatorname{Ar}=$

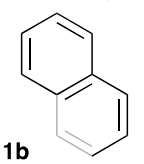

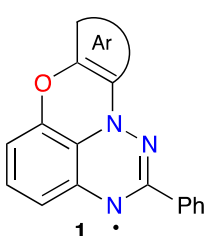

$X=\mathrm{NH}_{2}$ $t$-BuONO in $\mathrm{PhCl}$

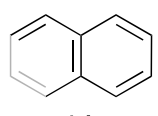

1d

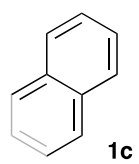

UV-Photoelectron Spectroscopy. The UV-PES spectra were recorded on a home-built (IPREM), three-part spectrometer equipped with a main body device, He I radiation source $\left(21.21 \mathrm{eV}\right.$ and/or $48 \mathrm{eV}$ ) and a $127^{\circ}$ cylindrical analyzer. The spectrometer works at constant analyzer energy under $5 \times 10^{-6} \mathrm{hPa}$ working pressure and $\leq 10^{-7} \mathrm{hPa}$ for channeltron $(\mathrm{X} 914 \mathrm{~L})$ pressure. The monitoring is done by a microcomputer supplemented by a digital-analogue converter (AEI spectrum). The spectra resulting from a single scan

contain 2048 points and are accurate within $0.05 \mathrm{eV}$. Spectra are calibrated with lines of xenon (12.13 and $13.44 \mathrm{eV}$ ) and of argon $(15.76$ and $15.94 \mathrm{eV})$. The accuracy of the measured ionization energies is $\pm 0.03 \mathrm{eV}$ for sharp peaks and $\pm 0.05 \mathrm{eV}$ for broad and overlapping signals. The samples were slowly vaporized under low pressure $\left(1.3 \times 10^{-6} \mathrm{hPa}\right)$ inside a homemade three-valve injector $(3 / 4$ in. diameter; $10 \mathrm{~cm}$ length; working temperature: $\left.-190{ }^{\circ} \mathrm{C} \leq \mathrm{T} \leq+300{ }^{\circ} \mathrm{C}\right)$, and the gaseous flow was simultaneously and continuously analyzed by a UV-photoelectron spectrometer. The evaporation was conducted at the following temperatures: $205^{\circ} \mathrm{C}$ for $\mathbf{1 b}\left(\mathrm{mp} 210^{\circ} \mathrm{C}\right), 275^{\circ} \mathrm{C}$ for $1 \mathrm{c}\left(\mathrm{mp} 249^{\circ} \mathrm{C}\right)$, and $260{ }^{\circ} \mathrm{C}$ for $1 d\left(\mathrm{mp} 219^{\circ} \mathrm{C}\right)$.

Computational Methods. All calculations were performed using the Gaussian $09^{12}$ computational package. Geometry optimizations were carried out with the UCAM$\mathrm{B}_{3} \mathrm{LYP}^{13-16}$ functional and the triple- $\zeta$ 6-311G $(\mathrm{d}, \mathrm{p})$ basis set. ${ }^{17}$ Frequency calculations were performed for the optimized geometries in order to verify that the stationary points obtained were true energy minima. Atomic spin densities summed up to heavy atoms in series 1 were obtained using Barone basis set $^{18}$ at the UCAM-B3LYP/EPR-III//UCAM$\mathrm{B} 3 \mathrm{LYP} / 6-311 \mathrm{G}(\mathrm{d}, \mathrm{p})$ level of theory in vacuum and also in benzene dielectric medium requested with the SCRF(IEFPCM, Solvent = Benzene) keyword $($ IEFPCM, the default PCM model).${ }^{19,20}$ Visualization of molecular orbitals was done with Avogadro software. ${ }^{21}$

Vertical $\mathrm{IE}_{n}$ were calculated using two methods at the UCAM-B3LYP/6-311G(d,p) level of theory as recently demonstrated for a series $C(10)$-substituted derivatives 1a. ${ }^{11}$ Thus, in the first, frequently used method ${ }^{22-24}$ the lowest ionization energy $\left(\mathrm{IE}_{1}\right)$ was calculated as $\Delta E_{\mathrm{SCF}}=E_{\mathrm{SCF} \text { cation }}-$ $E_{\mathrm{SCFradical}}$ for the fully optimized radical in its ground state and the cation at the radical geometry (single point calculations). Higher vertical ionization energies $\left(\mathrm{IE}_{n}\right)$ were obtained as a sum of $\Delta E_{\mathrm{SCF}}$ and $E_{\mathrm{TD}-\mathrm{DFT}(n)}$, where the latter is the $E_{n}$ excitation energy calculated with the TD method for the cation at the radical geometry. The TD method takes into account also low-lying ionic states, and this approach has been demonstrated to be particularly reliable for obtaining accurate ionization energies. ${ }^{25,26}$

In the second method, vertical ionization energies $\left(\mathrm{IE}_{n}\right)$ are calculated on the basis of Koopmans' theorem ${ }^{27}$ and 'shifted eigenvalue" correction. ${ }^{28}$ In this formalism adopted for analysis of open-shell molecules, the first ionization energy is $\mathrm{IE}_{1}^{\mathrm{KS}}=$ $-\varepsilon_{\mathrm{SOMO}}^{\mathrm{KS}}$, where $\varepsilon_{\mathrm{SOMO}}^{\mathrm{KS}}$ is the Kohn-Sham energy of the highest occupied MO (SOMO) of the radical in its ground state, obtained with the unrestricted method (UCAM-B3LYP/6$311 \mathrm{G}(\mathrm{d}, \mathrm{p}))$. Following the Stowasser and Hoffmann suggestion, ${ }^{28}$ ionization energies for the first and higher ionization can be calculated from Kohn-Sham orbital energy corrected by a constant factor $x$ as $\mathrm{IE}_{n}=-\varepsilon_{\mathrm{HOMO}-n+1}^{\mathrm{KS}}+x_{\Delta \mathrm{ESCF}}$, where the $\varepsilon_{\mathrm{HOMO}-n+1}^{\mathrm{KS}}$ for $n>1$ is obtained for fully geometry-optimized radical, using restricted open-shell method (RO-CAM-B3LYP/ $6-311 G(d, p))$. The "shifted eigenvalue" correction is calculated as $x_{\triangle \mathrm{ESCF}}=\mathrm{IE}_{1}^{\mathrm{ref}(\triangle \mathrm{ESCF})}-\mathrm{IE}_{1}^{\mathrm{KS}}$ using theoretical first ionization energy as the reference $\left(\mathrm{IE}_{1}^{\text {ref }}(\triangle \mathrm{ESCF})=\Delta E_{\mathrm{SCF}}=E_{\mathrm{SCF} \text { cation }}-\right.$ $E_{\mathrm{SCFradica}}$ vide supra; then $\left.x_{\Delta \mathrm{ESCF}}=\mathrm{IE}_{1}^{\text {ref }(\Delta \mathrm{ESCF})}-\mathrm{IE}_{1}^{\mathrm{KS}}\right)$. $^{29}$

\section{RESULTS AND DISCUSSION}

UV-photoelectron spectra were successfully measured for 1c and $\mathbf{1 d}$, and results together with selected MO contours are shown in Figure 2. For comparison purposes, Figure 2 also 


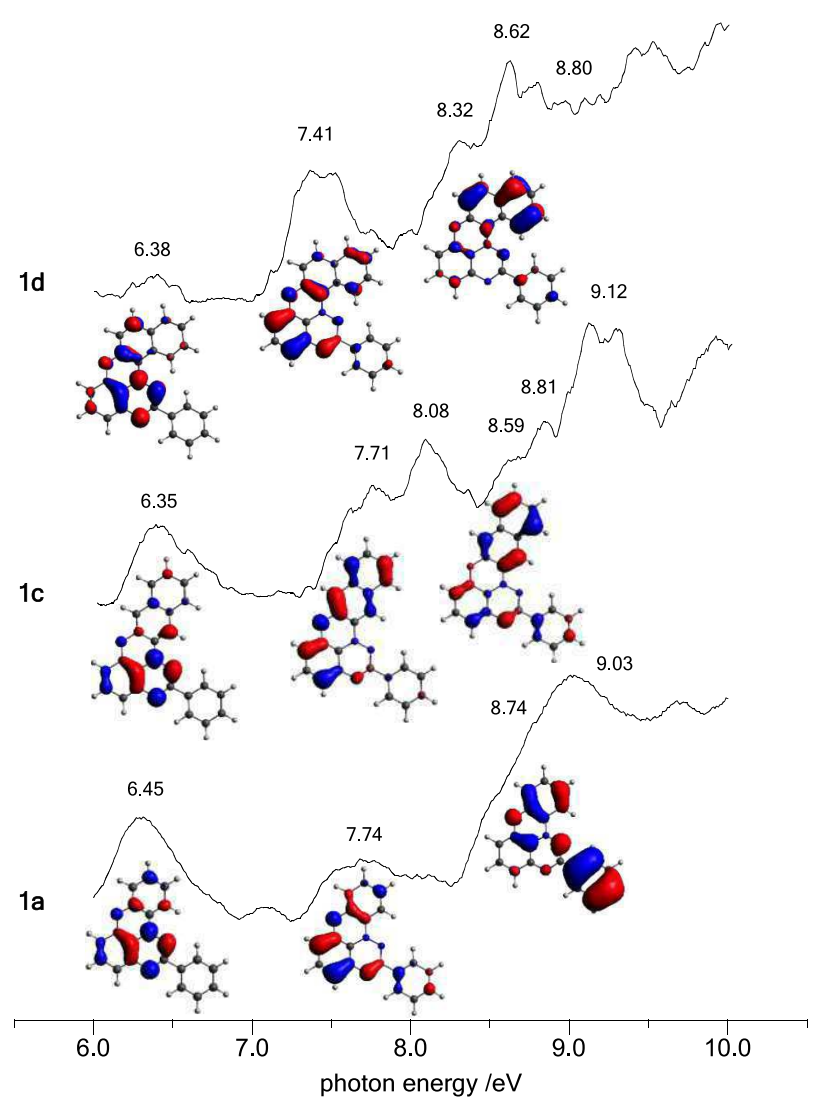

Figure 2. UV-photoelectron spectra of radicals 1a, 1c, and 1d with contours of three highest occupied MOs corresponding to the lowest $\mathrm{IE}_{n}$.

contains previously obtained data for 1a. Photoelectron spectra could not been obtained for $\mathbf{1 b}$ probably due to its insufficient vapor pressure and decomposition during evaporation of the liquid phase.

The lowest energy band in the PE spectra of $\mathbf{1 c}$ and for $\mathbf{1 d}$ is found at 6.35 and at $6.38 \mathrm{eV}$, respectively, and is ascribed to the SOMO, which is a $\pi$-type antibonding orbital extending mainly over rings $\mathrm{A}-\mathrm{D}$. The second $\mathrm{PE}$ band appears at 7.71 $\mathrm{eV}$ for $1 \mathrm{c}$ and $7.41 \mathrm{eV}$ for $\mathbf{1 d}$ and has the same character as the SOMO: $\pi$ antibonding extending over most of the heterocycle. The next higher energy PE band of $1 \mathrm{c}$ at $8.08 \mathrm{eV}$ is attributed to the HOMO-2 and corresponds to the antibonding $\mathrm{MO}$ extending over all aromatic rings. The HOMO-3 and the HOMO-4 (8.59 and $8.81 \mathrm{eV}$, respectively) are localized mainly on the $\mathrm{C}(2)$ - phenyl substituent. Finally, the band at $9.12 \mathrm{eV}$ is due to antibonding interactions of four aromatic rings and nitrogen lone pairs (HOMO-5).

For 1d, the UV-PES band at $8.32 \mathrm{eV}$ is also attributed to the $\mathrm{HOMO}-2$, localized mainly on rings $\mathrm{D}$ and $\mathrm{E}$, while $\mathrm{HOMO}-3$ at $8.62 \mathrm{eV}$ corresponds to the antibonding $\mathrm{MO}$ extending over the naphthalene fragment and the $\mathrm{C}(2)-$ phenyl substituent. The next band at $8.80 \mathrm{eV}$ contains two ionizations and is associated with the $\mathrm{HOMO}-4$, localized on the $\mathrm{C}(2)$ - phenyl substituent, and the HOMO-5 corresponding to the antibonding $\mathrm{MO}$ extending over all aromatic rings, with a contribution of nitrogen lone pairs. Full assignment of the observed bands to particular electronic states (MOs) for all members of series $\mathbf{1}$ is provided in the Supporting Information.

A comparison of experimental ionization energies $\mathrm{IE}_{n}$ for three derivatives with DFT-calculated ionization energies demonstrates that the best correlation is observed for data obtained using method 2. Analysis of data in Table 1 shows that DFT systematically underestimates $\mathrm{IE}_{n}$ by $0.06 \mathrm{eV}$ with the uncertainty of $\pm 0.03 \mathrm{eV}$, which is comparable to the experimental error. The particularly good performance of method 2 was noted before in analysis of a series of $\mathrm{C}(10)$ substituted derivatives of $1 \mathrm{a}$, in which the DFT-derived $\mathrm{IE}_{n}$ were underestimated by $0.04(2) \mathrm{eV} .^{11}$

The observed high accuracy of method 2 permits prediction of ionization energies for other $\pi$-extended derivatives of 1a with the experimental precision of $\pm 0.03 \mathrm{eV}$. Analysis of data in Table 1 shows that ionization energies have a tendency to decrease with increasing $\pi$-delocalization. Thus, fusing the benzene ring to 1 a lowers $\mathrm{IE}_{1}$ by about $0.1 \mathrm{eV}$ with the biggest difference for $\mathbf{1 b}$ isomer ( $k$ edge, $\Delta \mathrm{IE}_{1}=-0.12 \mathrm{eV}$ ). A much bigger effect of ring fusion is observed for $\mathrm{IE}_{2}$, which is moderately lower in the isomer with fusion at the $m$ edge $(\mathbf{1 d}$, $\left.\Delta \mathrm{IE}_{2}=-0.33 \mathrm{eV}\right)$ and strongly affected in isomer $\mathbf{1 b}(k$ edge, $\left.\Delta \mathrm{IE}_{1}=-0.63 \mathrm{eV}\right)$, while little impact on $\mathrm{IE}_{2}$ has fusion at edge $l\left(1 \mathrm{c}, \Delta \mathrm{IE}_{2}=-0.03 \mathrm{eV}\right)$.

Fusing the naphthalene ring with 1 a shows essentially the same, within the experimental error, lowering of $\mathrm{IE}_{1}$ by about $0.1 \mathrm{eV}$ relative to $1 \mathrm{a}$. As observed for benzo-fused systems, the biggest decrease in $\mathrm{IE}_{1}$ is observed for the $k$ edge in isomer $1 \mathrm{e}$ $\left(\Delta \mathrm{IE}_{1}=-0.15 \mathrm{eV}\right)$. Finally, periannulation with phenalene at

Table 1. Ionization Energies, $\mathrm{IE}_{1}$ and $\mathrm{IE}_{2}$, and Spin Delocalization Parameter $\mathrm{RDV}^{-1}$ for Radicals 1 and $\mathrm{A}$

\begin{tabular}{|c|c|c|c|c|c|c|c|c|}
\hline \multirow[b]{2}{*}{ compd } & \multicolumn{2}{|c|}{ experimental $\mathrm{IE}_{n} / \mathrm{eV}^{a}$} & \multicolumn{2}{|c|}{$\begin{array}{c}\text { DFT method } 1^{b} \\
\mathrm{IE}_{n}=\Delta E_{\mathrm{SCF}}+E_{\mathrm{TD}-\mathrm{DFT}} / \mathrm{eV}\end{array}$} & \multicolumn{3}{|c|}{ DFT method $2^{b} \mathrm{IE}_{n}=-\varepsilon^{\mathrm{KS}}+x_{\Delta S \mathrm{CF}} / \mathrm{eV}$} & \multirow[b]{2}{*}{$\mathrm{RDV}^{-1 c}$} \\
\hline & $\mathrm{IE}_{1}$ & $\mathrm{IE}_{2}$ & $\mathrm{IE}_{1}$ & $\mathrm{IE}_{2}$ & $\mathrm{IE}_{1}$ & $\mathrm{IE}_{2}$ & $x_{\Delta \mathrm{SCF}}$ & \\
\hline $\mathbf{A}^{d}$ & 6.40 & 7.98 & 6.41 & 7.70 & 6.41 & 7.97 & 0.319 & 3.538 \\
\hline $1 \mathbf{a}^{d}$ & 6.45 & 7.74 & 6.43 & 7.33 & 6.43 & 7.63 & 0.320 & 3.809 \\
\hline $1 b$ & $6.33^{e}$ & $7.11^{e}$ & 6.27 & 7.05 & 6.27 & 7.38 & 0.252 & 3.832 \\
\hline 1c & 6.35 & 7.71 & 6.39 & 7.32 & 6.39 & 7.53 & 0.245 & 3.789 \\
\hline $1 d$ & 6.38 & 7.41 & 6.28 & 7.07 & 6.28 & 7.40 & 0.257 & 3.628 \\
\hline 1e & $e$ & $e$ & 6.24 & 7.04 & 6.24 & 7.35 & 0.219 & 3.893 \\
\hline If & $e$ & $e$ & 6.31 & 7.17 & 6.31 & 7.35 & 0.208 & 3.906 \\
\hline $1 \mathrm{~g}$ & $e$ & $e$ & 6.28 & 7.08 & 6.28 & 7.37 & 0.205 & 3.718 \\
\hline $1 \mathrm{~h}$ & $e$ & $e$ & 6.25 & 6.96 & 6.25 & 7.00 & 0.183 & 3.877 \\
\hline
\end{tabular}

${ }^{a} \mathrm{UV}-\mathrm{PES}$; estimated accuracy $\pm 0.03 \mathrm{eV} .{ }^{b} \mathrm{IE}_{1}=\Delta E_{\mathrm{SCF}}=E_{\mathrm{SCF} \text { cation }}-E_{\mathrm{SCFradical}}$ at the UCAM-B3LYP/6-311G(d,p) level of theory. See text for details. ${ }^{c}$ Radical delocalization value obtained from spin densities using UCAM-B3LYP/EPR-III//UCAM-B3LYP/6-311G(d,p) in a vacuum. ${ }^{d}$ Reference 11. ${ }^{e}$ Calculated from relationship: $\operatorname{IE}_{n}(\mathrm{UVPES})=\mathrm{IE}_{n}(\mathrm{DFT})+0.06(3)$. 
edges $k$ and $l$ of 1 a has a moderate effect on both $\mathrm{IE}_{1}$ and $\mathrm{IE}_{2}$ in $\mathbf{1 h}$, which are lower than those in the parent $1 \mathbf{a}$, but similar to those in 1e (Table 1).

Lastly, the effect of $\pi$-extension on spin density distribution in radicals in series $\mathbf{1}$ was analyzed using an inverse of Radical Delocalization Value ${ }^{30}\left(\mathrm{RDV}^{-1}\right)$, which is a sum of square of DFT-derived spin densities on all heavy atoms $(\mathrm{RDV}=$ $\left.\Sigma\left(\rho_{i}\right)^{2}\right) .{ }^{11,31}$ Analysis of data in Table 1 shows that the $\mathrm{RDV}^{-1}$ value remains essentially unchanged, when the benzene ring is fused at edges $k$ and $l$ of $\mathbf{1 a}$, but it is markedly lower for isomer 1d (the $m$ edge). An analogous effect is observed for fusing the naphthalene ring: the $\mathrm{RDV}^{-1}$ value slightly increases for isomers 1e and 1f ( $k$ and $l$ edges), but it is lower for fusion at the $m$ edge ( $\mathbf{~ g}$ isomer). Periannulation of phenalene at edges $k, l$ of 1 a gives essentially the same effect in $\mathbf{1 h}$ as fusion of naphthalene in $\mathbf{1 e}$ and $\mathbf{1 f}$. This very modest spin delocalization in derivatives $\mathbf{1 b}-\mathbf{1 h}$ is in contrast with findings for the parent Blatter radical A: fusion of benzene at ring B of radicals $\mathbf{A}$ decreases spin concentration on the central $[1,2,4]$ triazinyl unit by $9.3 \%,{ }^{32}$ while the same fusion on ring D in flat Blatter radical 1a diminishes the total spin concentration by only 1$2.3 \%$, depending on the fusion edge.

The above analysis demonstrates, that the electron spin remains localized largely in rings $\mathrm{A}, \mathrm{C}$, and $\mathrm{D}$, as shown for $\mathbf{1 a}$ and $\mathbf{1 h}$ in Figure 3, essentially unaffected by $\pi$-extension of ring

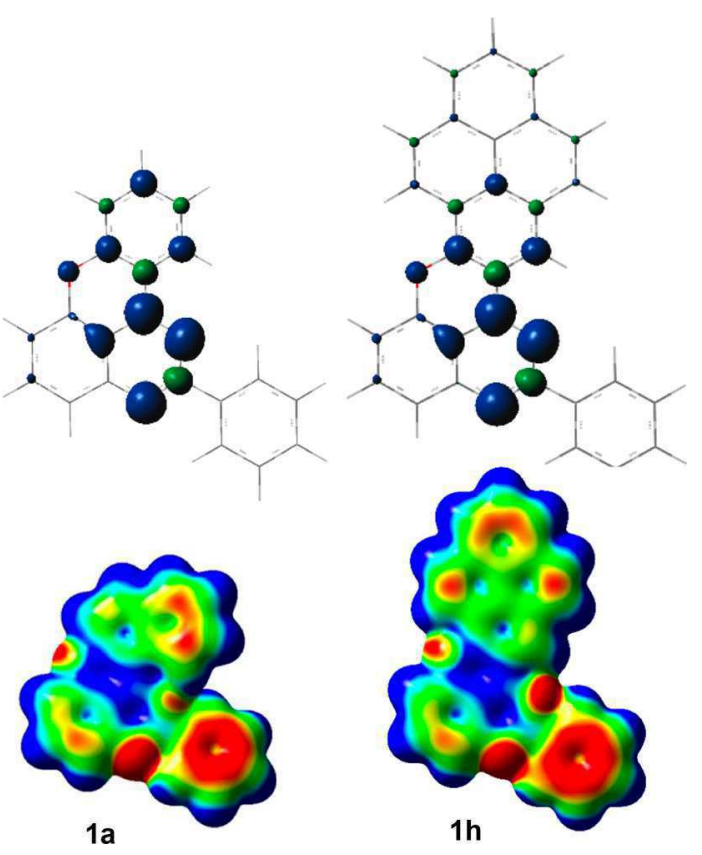

Figure 3. (Top) spin density map and (bottom) electrostatic potential surface map for $\mathbf{1 a}$ and $\mathbf{1 h}$ at the 0.004 electron/bohr ${ }^{3}$ and UCAM-B3LYP/6-311G(d,p) level of theory. ESP iso-contour level from +12.55 (red) to -12.55 (blue) $\mathrm{kcal} / \mathrm{mol}$.

D. Also, the electrostatic potential of the "lower" rings is little changed upon $\pi$-extension (Figure 3 ). These observations are consistent with the fact that spin delocalization onto "upper" rings $\mathrm{C}$ and $\mathrm{D}$ of 1a requires zwitterionic resonance structures (Figure 4) and thus is unfavorable.

\section{CONCLUSION}

Photoelectron results for radicals $\mathbf{1 c}$ and $\mathbf{1 d}$ combined with those for parent 1a and $\mathbf{A}$ revealed an excellent correlation

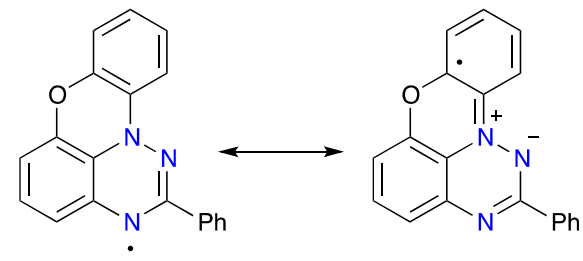

Figure 4. Two representative resonance structures for 1a.

with DFT computational results, which allowed us to assess $\mathrm{IE}_{1}$ for more highly delocalized systems. Detailed analysis of $\mathrm{IE}_{1}$ and spin delocalization in series $\mathbf{1}$ demonstrated only a modest impact of $\pi$-extension in the "upper" ring $\mathrm{D}$ of the parent planar Blatter radical 1a on its electronic properties. Thus, extension of $\pi$ system of 1 a by up to $10 \mathrm{sp}^{2}$-hybridized atoms in ring $\mathrm{D}$ resulted in lowering the ionization energy $\mathrm{IE}_{1}$ by 0.15 $\mathrm{eV}$ in $\mathbf{l h}$ with an average in the series of $-0.11(3) \mathrm{eV}$. Similarly, modest impact of $\pi$-system expansion on spin delocalization, measured by $\mathrm{RDV}^{-1}$, in series 1 was observed. Analysis also revealed some minor differences in these two parameters $\mathrm{IE}_{1}$ and $\mathrm{RDV}^{-1}$, between isomers and it appears that the biggest, although still small, impact is observed for $\pi$ system fusion at the $k$ edge of 1a. These findings and trends are consistent with the mechanism of electronic communication of the spin-supplying $[1,2,4]$ triazinyl (ring $A$ ) with ring $D$ of the parent 1a, which involves energetically unfavorable zwitterionic resonance structures.

\section{ASSOCIATED CONTENT}

\section{Supporting Information}

The Supporting Information is available free of charge at https://pubs.acs.org/doi/10.1021/acs.jpca.0c07900.

Enlarged Figure 2 and details of DFT calculations, which include geometrical parameters, ionization energies, $\mathrm{MO}$ contours, spin density and electrostatic potential maps, and coordinates of the DFT optimized radicals (PDF)

\section{AUTHOR INFORMATION}

\section{Corresponding Authors}

Piotr Kaszyński - Faculty of Chemistry, University of Łódź, 91-403 Łódź, Poland; Centre of Molecular and Macromolecular Studies, Polish Academy of Sciences, 90-363 Łódź, Poland; Department of Chemistry, Middle Tennessee State University, Murfreesboro, Tennessee 37130, United States; 이잉.org/0000-0002-2325-8560;

Email: piotr.kaszynski@mtsu.edu

Anna Chrostowska - Université de Pau et des Pays de l'Adour, E2S UPPA, CNRS, IPREM, 5254 Pau, France; Email: anna.chrostowska@univ-pau.fr

\section{Authors}

Aniket A. Hande - Université de Pau et des Pays de l'Adour, E2S UPPA, CNRS, IPREM, 5254 Pau, France; (1) orcid.org/0000-0001-6397-3174

Patrick Baylère - Université de Pau et des Pays de l'Adour, E2S UPPA, CNRS, IPREM, 5254 Pau, France

Complete contact information is available at: https://pubs.acs.org/10.1021/acs.jpca.0c07900 


\section{Author Contributions}

The manuscript was written through contributions of all authors. All authors have given approval to the final version of the manuscript.

\section{Notes}

The authors declare no competing financial interest.

\section{ACKNOWLEDGMENTS}

Financial support was provided by National Science Center (2017/25/B/ST5/02851) and Foundation for Polish Science (TEAM/2016-3/24). A.A.H. thanks E2S UPPA, ERASMUS $+\mathrm{D}$, and PROM for financial support.

\section{ABBREVIATIONS}

UV-PES, ultraviolet photoelectron spectroscopy; TD-DFT, time dependent density functional theory; SOMO, singly occupied molecular orbital; HOMO, highest occupied molecular orbital; LUMO, lowest unoccupied molecular orbital

\section{REFERENCES}

(1) Constantinides, C. P.; Koutentis, P. A. Stable N- and N/S-Rich Heterocyclic Radicals: Synthesis and Applications. Adv. Heterocycl. Chem. 2016, 119, 173-207.

(2) Blatter, H. M.; Lukaszewski, H. A New Stable Free Radical. Tetrahedron Lett. 1968, 9, 2701-2705.

(3) Ciccullo, F.; Calzolari, A.; Bader, K.; Neugebauer, P.; Gallagher, N. M.; Rajca, A.; van Slageren, J.; Casu, M. B. Interfacing a Potential Purely Organic Molecular Quantum Bit with a Real-Life Surface. ACS Appl. Mater. Interfaces 2019, 11, 1571-1578.

(4) Low, J. Z.; Kladnik, G.; Patera, L. L.; Sokolov, S.; Lovat, G.; Kumarasamy, E.; Repp, J.; Campos, L. M.; Cvetko, D.; Morgante, A.; Venkataraman, L. The Environment-Dependent Behavior of the Blatter Radical at the Metal-Molecule Interface. Nano Lett. 2019, 19, $2543-2548$

(5) Zheng, Y.; Miao, M.-s.; Dantelle, G.; Eisenmenger, N. D.; Wu, G.; Yavuz, I.; Chabinyc, M. L.; Houk, K. N.; Wudl, F. A Solid-State Effect Responsible for an Organic Quintet State at Room Temperature and Ambient Pressure. Adv. Mater. 2015, 27, 1718-1723.

(6) Bejarano, F.; Olavarria-Contreras, I. J.; Droghetti, A.; Rungger, I.; Rudnev, A.; Gutiérrez, D.; Mas-Torrent, M.; Veciana, J.; van der Zant, H. S. J.; Rovira, C.; Burzur1', E.; Crivillers, N. Robust Organic Radical Molecular Junctions Using Acetylene Terminated Groups for C-Au Bond Formation. J. Am. Chem. Soc. 2018, 140, 1691-1696.

(7) Kaszynski, P.; Constantinides, C. P.; Young, V. G., Jr. The Planar Blatter Radical: Structural Chemistry of 1,4-Dihydrobenzo[e][1,2,4]triazin-4-yls. Angew. Chem., Int. Ed. 2016, 55, 11149-11152.

(8) Bartos, P.; Anand, B.; Pietrzak, A.; Kaszyński, P. Functional Planar Blatter Radical through Pschorr-Type Cyclization. Org. Lett. 2020, 22, 180-184.

(9) Bartos, P.; Young, V. G., Jr.; Kaszyński, P. Ring-Fused 1,4Dihydro[ $[1,2,4]$ triazin-4-yls through Photocyclization. Org. Lett. 2020, $22,3835-3840$.

(10) Shivakumar, K. I.; Pociecha, D.; Szczytko, J.; Kapuściński, S.; Monobe, H.; Kaszyński, P. Photoconductive Bent-Core Liquid Crystalline Radicals with a Paramagnetic Polar Switchable Phase. J. Mater. Chem. C 2020, 8, 1083-1088.

(11) Hande, A. A.; Darrigan, C.; Bartos, P.; Baylère, P.; Pietrzak, A.; Kaszyński, P.; Chrostowska, A. UV-Photoelectron Spectroscopy of Stable Radicals: The Electronic Structure of Planar Blatter Radicals as Materials for Organic electronic. Phys. Chem. Chem. Phys. 2020, 22, 23637-23644.

(12) Frisch, M. J.; Trucks, G. W.; Schlegel, H. B.; Scuseria, G. E.; Robb, M. A.; Cheeseman, J. R.; Scalmani, G.; et al. Gaussian 09, Revision D.01; Gaussian, Inc.: Wallingford, CT, 2013.
(13) Becke, A. D. Density-Functional Exchange-Energy Approximation with Correct Asymptotic Behavior. Phys. Rev. A: At., Mol., Opt. Phys. 1988, 38, 3098-3100.

(14) Becke, A. D. Density Functional Thermochemistry. III. The Role of Exact Exchange. J. Chem. Phys. 1993, 98, 5648-5652.

(15) Lee, C.; Yang, W.; Parr, R. G. Development of the ColleSalvetti Correlation-Energy Formula into a Functional of the Electron Density. Phys. Rev. B: Condens. Matter Mater. Phys. 1988, 37, 785789.

(16) Yanai, T.; Tew, D. P.; Handy, N. C. A New Hybrid ExchangeCorrelation Functional Using the Coulomb-Attenuating Method (CAM-B3LYP). Chem. Phys. Lett. 2004, 393, 51-57.

(17) Krishnan, R.; Binkley, J. S.; Seeger, R.; Pople, J. A. Selfconsistent Molecular Orbital Methods. XX. A Basis Set for Correlated Wave Functions. J. Chem. Phys. 1980, 72, 650-654.

(18) Barone, V. Structure, Magnetic Properties and Reactivities of Open-Shell Species from Density Functional and Self-Consistent Hybrid Methods In Recent Advances in Density Functional Methods; Chong, D. P., Ed.; World Scientific Publ. Co.: Singapore, 1996; Vol. 1, p 287-334.

(19) Cossi, M.; Scalmani, G.; Rega, N.; Barone, V. New Developments in the Polarizable Continuum Model for Quantum Mechanical and Classical Calculations on Molecules in Solution. J. Chem. Phys. 2002, 117, 43-54. and references therein.

(20) Barone, V.; Cossi, M.; Tomasi, J. A New Definition of Cavities for the Computation of Solvation Free Energies by the Polarizable Continuum Model. J. Chem. Phys. 1997, 107, 3210-3221.

(21) Hanwell, M. D.; Curtis, D. E.; Lonie, D. C.; Vandermeersch, T.; Zurek, E.; Hutchison, G. R. Avogadro: An Advanced Semantic Chemical Editor, Visualization, and Analysis Platform. J. Cheminf. 2012, 4, 17

(22) Bartnik, R.; Baylère, P.; Chrostowska, A.; Galindo, A.; Leśniak, S.; Pfister-Guillouzo, G. Flash Vacuum Thermolysis of 1Azabicyclo[1.1.0]butanes. Photoelectron Spectrum of 3-Phenyl-2azabuta-1,3-diene. Eur. J. Org. Chem. 2003, 2003, 2475-2479.

(23) Chrostowska, A.; Matrane, A.; Maki, D.; Khayar, S.; Ushiki, H.; Graciaa, A.; Belachemi, L.; Guillemin, J.-C. Are Unsaturated Isocyanides so Different from the Corresponding Nitriles? ChemPhysChem 2012, 13, 226-236.

(24) Vu, T. Y.; Chrostowska, A.; Huynh, T. K. X.; Khayar, S.; Dargelos, A.; Justyna, K.; Pasternak, B.; Leśniak, S.; Wentrup, C. New Reactions of $\mathrm{N}$-tert-Butylimines; Formation of N-Heterocycles by Methyl Radical Elimination on Flash Vacuum Thermolysis of $\mathrm{N}$ Benzylidene- and N-(2-Pyridylmethylidene)-tert-butylamines. Chem. Eur. J. 2013, 19, 14983-14988.

(25) Lemierre, V.; Chrostowska, A.; Dargelos, A.; Chermette, H. Calculation of Ionization Potentials of Small Molecules: A Comparative Study of Different Methods. J. Phys. Chem. A 2005, $109,8348-8355$.

(26) Stratmann, R. E.; Scuseria, G. E.; Frisch, M. J. An Efficient Implementation of Time-Dependent Density-Functional Theory for the Calculation of Excitation Energies of Large Molecules. J. Chem. Phys. 1998, 109, 8218-8224.

(27) Koopmans, T. Über die Zuordnung von Wellenfunktionen und Eigenwerten zu den Einzelnen Elektronen Eines Atoms. Physica 1934, $1,104-113$.

(28) Stowasser, R.; Hoffmann, R. What Do the Kohn-Sham Orbitals and Eigenvalues Mean? J. Am. Chem. Soc. 1999, 121, 34143420.

(29) Mazière, A.; Chrostowska, A.; Darrigan, C.; Dargelos, A.; Graciaa, A.; Chermette, H. Electronic Structure of BN-Aromatics: Choice of Reliable Computational Tools. J. Chem. Phys. 2017, 147, 164306.

(30) De Vleeschouwer, F.; Chankisjijev, A.; Yang, W.; Geerlings, P.; De Proft, F. Pushing the Boundaries of Intrinsically Stable Radicals: Inverse Design Using the Thiadiazinyl Radical as a Template. J. Org. Chem. 2013, 78, 3151-3158.

(31) For details, see the Supporting Information. 
(32) Bajaj, A.; Ali, M. E. First Principle Designing of Blatter's Diradicals with Strong Ferromagnetic Exchange Interactions. J. Phys. Chem. C 2019, 123, 15186-15194. 